\title{
ETHNICITY, BODY SHAPE DIFFERENCES AND FEMALE CONSUMERS' APPAREL FIT PROBLEMS
}

\author{
Bukisile P. Makhanya ${ }^{1}$, Helena M. de Klerk ${ }^{1}$, Karien Adamski ${ }^{2}$, Anne Mastamet- \\ Mason $^{3}$ \\ ${ }^{1}$ Department of Consumer Science, University of Pretoria, South Africa \\ ${ }^{2}$ Department of Statistics, University of Pretoria, South Africa \\ ${ }^{3}$ Department of Fashion Design, Tshwane University of Technology, South Africa
}

Corresponding Author

Helena M. de Klerk

Department of Consumer Science

University of Pretoria

Pretoria

0001

South Africa

E-mail: helena.deklerk@up.ac.za

\begin{abstract}
This research compared body shapes, measurements, ratios and fit problems of 234 African (109) and Caucasian (125) women. A 3-dimensional (3D) full body scanner generated virtual body images from which circumferential, width, protrusion and height measurements were extracted. Thereafter, circumferential and height ratios were computed. Drop values of key circumferential measurements were used to classify participants' bodies; these were later visually confirmed and adopted. Results revealed that the triangle, hourglass and rectangle were the three most predominant shapes amongst African and Caucasian women. There was a significant association between the three most predominant body shapes and ethnicity. There were significant differences in some body measurements and ratios, most of which were observed between African and Caucasian triangle shapes, as well as in some of the other body shapes and the Caucasian hourglass used in the apparel industry. The differences especially between the Caucasian hourglass and the other body shapes may be the root cause of the persistent fit problems reported by some of the
\end{abstract}


predominant body shapes at some of the selected body parts. This study therefore, concluded that multi-cultural markets need to identify characteristics of all prevalent shapes within a population in order to minimise apparel fit problems.

\section{Keywords}

Body shape, fit problems, female, drop value, 3D body scanning, ethnicity

\section{Introduction}

Living in a consumer-driven era, the challenge to apparel industries is not only about giving customers extra choices, but rather to contain consumers' individual preferences. Female body shapes and proportions vary and change over time, as the result of, amongst others, nutritional changes, lifestyles and ethnicity. These differences have an impact on apparel fit (Hillestad, 1980:121; Winks, 1997:20; Ashdown, 1998; Simmons \& Istook, 2003). Ready-to-wear apparel fit problems have gained a lot of attention as consumer demand for well-fitted apparel increases. Dissatisfaction with fit is however still one of the most frequently stated problems with garment purchases. Women have been reported as the most dissatisfied consumers (DeLong et al., 1993; Alexander et al., 2005; Otieno et al., 2005).

Dimensions from the human body underpin an effective sizing system and consequently better-fitting apparel items. Sizing systems originate from people's measurements and body shapes (Bye et al., 2006:66; Petrova in Ashdown, 2007:56). Ashdown (2000) sees sizing systems as the focus around which all the factors concerning sizing and fit revolve. She has identified the main factors affecting sizing systems and consequently the fit of ready-to-wear apparel as the population measures (body measurements), the design features (construction of the apparel), the fit issues (fit quality management), and the communication of sizing and fit (size labelling). To improve apparel fit, body measurements and major body shape variations prevalent within a consumer population must therefore be considered (Devarajan \& Istook, 2004; Bye et al., 2006; Petrova in Ashdown, 2007:57). Worldwide, apparel industries still mainly manufacture women's apparel that would fit only the ideal body shape properly. Consumers that differ in body shape characteristics from the ideal figure are 
therefore likely to experience fit problems from the standard apparel. A study by Simmons et al. (2004) confirms the diversity of body shapes within populations. From a sample of 222 women, $40 \%$ were bottom-heavy hourglass, $21.6 \%$ hourglass, $17.1 \%$ spoon, and $15.8 \%$ of rectangular shape. The findings of Pisut and Connell (2007) reveal that women are becoming larger than the ideal figure and reflect different body shapes and sizes than in previous decades (Simmons et al., 2004). In another study, Lee et al. (2004) discovered that the most prevalent body shape among USA and Korean women was the rectangle and not the ideal (hourglass) figure. Apparel manufacturers therefore need to understand body shape differences within populations in order to produce apparel with satisfactory fit.

In many Western countries, variations in female consumers' body shape are to a large extent attributed to the diverse ethnic groups. Lee et al. (2007) recorded that body shapes, sizes and proportions differ between ethnic groups and emphasised the need to study them as a way to increase consumer fit satisfaction with standardised apparel across the diverse ethnic groups. In this study, the African and Caucasian ethnic groups form part of the varied South African ethnic groups. Findings of a study by Winks (1997) revealed that body dimensions of Black South African males were generally smaller than those of Caucasian South African males. This might also hold true for African and Caucasian South African women.

Categorising body shapes and comparing body measurements and ratios of the different ethnic groups are imperative to determine the differences. Moreover, differently shaped consumers require differently shaped apparel to accommodate figure variations (Anderson et al., 2001; Fan et al., 2004; Connell et al., 2007). According to Connell et al. (2006), the classification of female body shapes within a specific country is, however, a challenge due to variations within and across ethnically homogeneous and heterogeneous populations. Pisut and Connell (2007) suggested that when constructing ready-to-wear apparel for a diverse target population, it is crucial that attention is directed at existing differences in figure shape characteristics in order to minimise fit problems.

As in most other countries, the South African apparel industry still does not cater for figure shape variations (Strydom \& De Klerk, 2006). They continue to base apparel 
production on the body shape and measurements of an ideal figure (Western hourglass) (Goldsberry et al., 1996; Anderson et al., 2001; Alexander et al., 2005). As a result, female consumers with body proportions that differ from the ideal figure may experience ready-to-wear apparel fit problems. Therefore, it is imperative to investigate how the female body shapes and body shape characteristics of diverse populations such as the South African population compare with each other and differ from the ideal figure. This could help to determine whether the use of the standard apparel shape and measurements would still give satisfactory fit across all ethnic groups. Otherwise, the ready-to-wear apparel fit problems currently experienced will persist. This study therefore sought to identify and compare the most prevalent body shapes, body shape characteristics and apparel fit problems of young African and Caucasian women in South Africa.

\section{Literature}

Body shapes have in the past mostly been classified by the drop of key circumferential measurements into the current hourglass, triangle, rectangular, apple and inverted triangle shapes (Chun-Yoon \& Jasper 1996; Winks 1997; Beazley 1998; Gupta \& Gangadhar 2004; Yu 2004:185). According to Simmons et al. (2004), a typical hourglass shape has bust and hips that are almost equal, with a moderate waist indentation. The rectangular body shape has hips and bust that are fairly equal and almost aligned, with little or no indentation at the waist, and has low bust to waist and hip to waist ratios. The oval body shape has the stomach, waist and abdomen measurements larger than the bust, with folds around the midsection compared to the rest of the body. The triangular shape has a larger hip circumference than bust, with no defined waistline and a low hip to waist ratio. An inverted triangular shape has a larger bust circumference than hips, with no defined waist line and a small bust to waist ratio. The extent to which a body deviates in shape and size from the ideal body shape used by the apparel industry in the manufacturing of women's apparel, may result in fit problems for those consumers with different body shapes.

Connell et al. (2006) categorised body shapes by using the relationship of the whole body to the front and side view perspectives, while Ashdown (2003) evaluated body protrusion from the front, side and back views of the body to differentiate between 
bodies that have the same circumferential proportions but different width and depth proportions. Simmons et al. (2004) undertook a study to come up with the Female Figure Identification Technique (FFIT) software. Literature was then used to identify body shapes as well as visual and descriptive information that helped to eventually also develop mathematical formulae for the FFIT software. The studies by Connell et al. (2006) and Simmons et al. (2004a) came up with body shape descriptors and not specific body shape parameters. Lee et al. (2007) utilised the FFIT software and also successfully came up with body shape defining parameters to classify United States (US) and Korean women. They further anticipated that the same parameters may be used successfully to classify other random US samples, with no mention of how successful it would be in different populations.

Despite these research findings, apparel industries keep on failing to satisfy different female consumer populations with different body shapes, by using dimensions and shapes of the Western standard or ideal figure. While body shape descriptors of different populations may be similar, defining parameters could be different and may be specific to each population. We reason that, since body shapes, size and proportions of South African women most probably differ from those of US women, body shape parameters that classified US and Korean women cannot successfully be used to classify South African women. Therefore, in this study, the parameters and mathematical formulae used by Lee et al. (2007) had to be modified based on the key dimensions of African and Caucasian women from South Africa. Moreover, Mastamet-Mason (2008) successfully modified the Western body shape parameters to determine ranges for the predominant Kenyan body shapes within maximum and minimum drop values, and suggested that the use of body shape descriptors alone does not take proportions into considerations. Mastamet-Mason and De Klerk (2012) further suggested using also visual sensory evaluation which could adequately address the visual analysis of the body. 


\section{Methodology}

\section{Sampling}

The targeted population of this study was African and Caucasian women aged 18 to 25 years. Large manufacturers and apparel retailers generally target this age group. They are young mature women with fully developed bodies and are considered to be fashion conscious. This consumer segment belongs to the Echo Boom or Generation Y consumer segment, a group that is racially diverse and seeks fashionable apparel that is flattering and will make them look attractive and show off their physical attributes, in order to satisfy emotional needs, to impress and be accepted by others. They were students from two large Universities in Tshwane, a major metropolitan city in South Africa. Purposive and snowball sampling techniques were used. Participants were recruited through e-mails, campus news, posters and word of mouth. A total sample of 234 was obtained, consisting of 109 African and 125 Caucasian, women after considering similar sample sizes that were used previously in other studies that utilised scan data.

\section{Data collection}

A (TC $)^{2}$ NX-12 3D body scanner was used in this study. Body scanning is regarded as the most reliable and accurate body measurement method (Istook \& Hwang, 2001; Xu et al., 2002; Ashdown, 2003; Simmons \& Istook, 2003; Devarajan \& Istook, 2004; Yu in Fan et al., 2004:171; Ashdown, 2007:xix; Wang et al., 2007). Participants wore two-piece scanning garments made from light grey stretchy, single-knit fabric with a fibre content of $95 \%$ cotton and 5\% lycra over their everyday well-fitting undergarments. Subjects were scanned until a good quality image was obtained in the normal scanning posture, i.e. feet $35 \mathrm{~cm}$ apart, and arms hanging away from the torso, as suggested in ISO/DIS 20685 (2010). Thereafter, circumferential, width, protrusion and height measurements were extracted at the bust, stomach, waist, abdomen, buttock, hip and thigh areas. These are critical fit points that are crucial in the classification of body shapes. Then the circumferential and height ratios were computed. Participants also completed questionnaires on, among others, apparel fit problems they experienced at each of the selected body parts. 


\section{Body shape classification procedure}

Defining parameters within the maximum and minimum range of drop values were calculated and used to identify distinctive body shapes in this study (refer to Table 1). The difference in hip and bust circumferences was used to first classify triangle and inverted triangle shapes. Once a body was classified it was no longer subjected to further classification using the bust and waist relationship, which was used to classify hourglass, rectangle and apple shapes. Body shapes assigned from measurements were confirmed and adopted after visual analysis of scanned images.

Table 1 Body shape categories and defining parameters

\begin{tabular}{|c|c|c|c|c|c|}
\hline \multirow[b]{2}{*}{ Drop values } & \multirow[b]{2}{*}{ Body shapes } & \multicolumn{3}{|c|}{ Defining parameters } & \multirow[b]{2}{*}{ Defining formulae } \\
\hline & & $\begin{array}{c}\text { Mean } \\
12.6\end{array}$ & $\begin{array}{c}\text { Std. dev. } \\
5.7\end{array}$ & $\begin{array}{l}\text { Min - Max } \\
0.09-29.8\end{array}$ & \\
\hline \multirow{3}{*}{ hip - bust } & Triangle & \multicolumn{3}{|c|}{ Mean to Max } & $12.6 \leq$ hip - bust $\leq 29.8$ \\
\hline & Inverted triangle & \multicolumn{3}{|c|}{ hip - bust $<0$} & hip - bust $<0$ \\
\hline & & $\begin{array}{c}\text { Mean } \\
18\end{array}$ & $\begin{array}{c}\text { Std. dev. } \\
4.1\end{array}$ & $\begin{array}{l}\text { Min - Max } \\
-3.7-26.6\end{array}$ & \\
\hline \multirow{3}{*}{ bust - waist } & Hourglass & \multicolumn{3}{|c|}{ Mean $\leq$ bust - waist $\leq$ Max } & $18 \leq$ bust - waist $\leq 26.6$ \\
\hline & Rectangular & \multicolumn{3}{|c|}{ Mean -3 x std. dev. $<$ bust - waist $<$ mean } & $5.6<$ bust - waist $<18$ \\
\hline & Apple & \multicolumn{3}{|c|}{ Minimum $\leq$ bust - waist $\leq-3 \times$ std. dev. } & $-3.7 \leq$ bust - waist $\leq 5.6$ \\
\hline
\end{tabular}

(Adapted from Lee et al., 2007; Mastamet-Mason, 2008). Measurements are in cm.

\section{Data analysis}

Descriptive statistics, e.g. frequencies, mean, median, standard deviation as well as percentages, were used to analyse measurement data. The Chi-square test was conducted to determine whether body shape prevalence varied by ethnic group at a $5 \%$ level of significance. The Kruskal-Wallis test was also used to establish which body shapes recorded significant differences in body measurements and ratios at each of the selected body parts at a 5\% level of significance. Body shapes with body measurements and ratios that recorded significant differences were further subjected to post hoc tests for planned pair-wise comparison, to determine which body shape pairs had significantly different measurements and ratios at each body part. 
Comparisons of interest in this study were similar African and Caucasian body shapes, e.g. African and Caucasian hourglass shapes and African and Caucasian triangle, African and Caucasian rectangle with the Caucasian (Western) hourglass shape that is currently used by the apparel industry. Thereafter, percentages were used to summarise the ready-to-wear apparel fit problems reported by the different body shapes at each of the selected body parts.

\section{Results and discussion}

\section{Body shape classification}

The most prevalent body shapes among the African group $(n=109)$ were the triangle (58.7\%), followed by the hourglass $(27.5 \%)$ and the rectangular shape $(12.8 \%)$. The least common was the apple shape $(0.9 \%)$. Among the Caucasian group $(n=125)$, the hourglass shape $(40.8 \%)$ was the most common, followed by the triangle $(33.6 \%)$ and the rectangle (25.6\%). There were no participants classified as apple-shaped among the Caucasian group. There were also no participants classified as inverted triangle among both ethnic groups (Table 2).

Table 2 Body shape classification by ethnic group

\begin{tabular}{|c|c|c|c|c|}
\hline \multirow[t]{2}{*}{$\begin{array}{c}\text { Body shape } \\
\text { categories }\end{array}$} & \multicolumn{3}{|c|}{ Classification by ethnic group } & \multirow{2}{*}{$\begin{array}{c}X^{2} \\
\text { p-value }\end{array}$} \\
\hline & $\begin{array}{c}\text { African } \\
\mathrm{n}(\text { col. \%) }\end{array}$ & $\begin{array}{c}\text { Caucasian } \\
\mathrm{n}(\text { col. \%) }\end{array}$ & $\begin{array}{c}\text { Total } \\
\text { n (col. \%) }\end{array}$ & \\
\hline Triangle & $64(58.7)$ & $42(33.6)$ & $106(45.3)$ & \multirow[t]{3}{*}{0.0004} \\
\hline Hourglass & $30(27.5)$ & $51(40.8)$ & $81(34.6)$ & \\
\hline Rectangle & $14(12.8)$ & $32(25.6)$ & $46(19.7)$ & \\
\hline Apple* $^{*}$ & $1(0.9)$ & $0(0)$ & $1(0.4)$ & \\
\hline Total & $109(47)$ & $125(53)$ & $234(100)$ & \\
\hline
\end{tabular}

Table 2 shows that there was a significant association between body shape prevalence (of the three predominant shapes) and ethnicity $(\mathrm{p}=0.004)$, as the order of predominant body shapes differed among the African and Caucasian women. 
Comparison of selected body measurements and ratios for similar African and Caucasian body shapes

The Kruskal-Wallis test of paired similar African and Caucasian body shapes (Table 3) revealed that:

African and Caucasian triangle: The thigh circumference of the African triangle was $4.2 \mathrm{~cm}$ more than that of the Caucasian triangle, and the total body to waist and total body to hip height ratios of the Caucasian triangle were significantly higher than those of the African triangle (indicated with \#, $\#^{1}$ and \# respectively).

African and Caucasian hourglass: The abdomen circumference, the abdomen width and the abdomen protrusion of the African hourglass, significantly were $5 \mathrm{~cm}, 3.2 \mathrm{~cm}$ and $3.5 \mathrm{~cm}$ less than those of the Caucasian hourglass, respectively (indicated with *, \# and *). Furthermore, the Caucasian hourglass females were significantly taller than the African hourglass females, as they recorded higher total body, bust and waist height measurements with $6.2 \mathrm{~cm}, 4.8 \mathrm{~cm}$ and $3.5 \mathrm{~cm}$ mean differences respectively, as indicated with *,\# and *.

African and Caucasian rectangle: The African rectangle females were significantly shorter $(8 \mathrm{~cm})$ and recorded significantly lower total body to waist height ratios than the Caucasian rectangular females, as indicated in Table 3 by $\#^{3}$ and $\#^{2}$ respectively.

\section{Comparison of selected body measurements and ratios for the Caucasian hourglass and the other body shapes}

In order to predict any fit problems, selected body measurements and the ratios of all the other African and Caucasian shapes were compared to those of the Caucasian hourglass - the one most often used by the apparel industry for sizing.

Caucasian hourglass and African and Caucasian triangle: The triangular African and Caucasian shapes had significantly smaller bust circumferences $(4.6 \mathrm{~cm}$ and 5.8 $\mathrm{cm}$ mean differences respectively) and smaller bust protrusions $(2.7 \mathrm{~cm}$ and $3.8 \mathrm{~cm}$ 


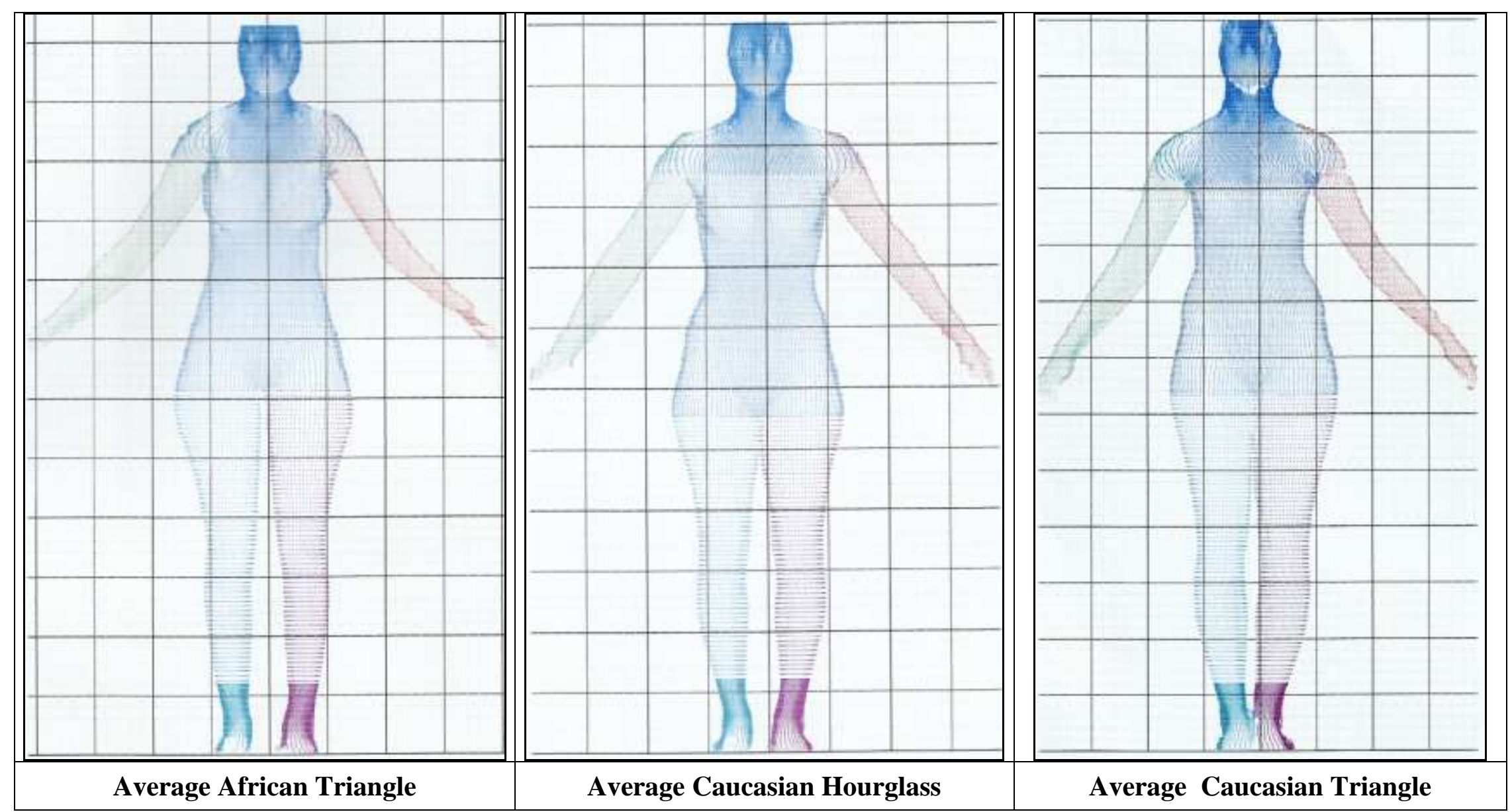

Figure 1 Comparison of African and Caucasian triangle and Caucasian hourglass body shapes 
respectively), as well as higher hip widths (1.9 $\mathrm{cm}$ and $1.6 \mathrm{~cm}$ respectively), and significantly lower bust to waist, lower bust to hip, and higher hip to waist ratios than the Caucasian hourglass (differences indicated by * and \#). The African triangle also had significantly larger hip, seat and thigh circumferences $(6.2 \mathrm{~cm}, 4.8 \mathrm{~cm}$ and $4.3 \mathrm{~cm}$ mean differences respectively), and a smaller abdomen width ( $2 \mathrm{~cm}$ mean difference) than the Caucasian hourglass shape (as indicated by * and \#). The African triangle was significantly shorter and recorded a lower bust height than the Caucasian hourglass. The Caucasian hourglass also had significantly higher bust to waist and bust to hip, and lower hip to waist circumferential ratios than the Caucasian and African triangle. These differences are also clearly visible on the scanned body images (Figure 1).

Caucasian hourglass and African and Caucasian rectangle: Table 3 also shows that the Caucasian rectangle had a significantly wider waist ( $2.5 \mathrm{~cm}$ mean difference), resulting in significantly lower bust to waist and hip to waist ratios than the Caucasian hourglass (as indicated by $*, \#^{1}, \#^{2}$ and $\#^{3}$ respectively). The Caucasian rectangle also had a significantly higher total body to waist height ratio than the Caucasian hourglass. On the other hand, the African rectangle was significantly shorter and recorded significantly lower bust height as well as bust to waist ratios than the Caucasian hourglass (Table 3).

\section{Perceived fit problems}

The participants indicated their experiences of tight, loose or no problems with the fit at the selected body parts of ready-to-wear apparel. Since there were three fit categories, over $40 \%$ of the participants in each fit category per body shape was regarded as a majority and were indicated by bold figures with asterisks (*). Below $40 \%$ was regarded as a minority. Comparisons of reported fit problems were between similar African and Caucasian body shapes and also between the Caucasian hourglass and the other African and Caucasian body shapes (Table 4).

\section{Comparison of fit problems of the Caucasian hourglass and the African and} Caucasian triangle: Comparison of measurements revealed that both triangular 


\begin{tabular}{|c|c|c|c|c|c|c|c|c|}
\hline Dimension & $\begin{array}{l}\text { African } \\
\text { Triangle }\end{array}$ & $\begin{array}{c}\text { Caucasian } \\
\text { Triangle }\end{array}$ & $\begin{array}{c}\text { African } \\
\text { Hourglass }\end{array}$ & $\begin{array}{l}\text { Caucasian } \\
\text { Hourglass }\end{array}$ & $\begin{array}{c}\text { African } \\
\text { Rectangle }\end{array}$ & $\begin{array}{l}\text { Caucasian } \\
\text { Rectangle }\end{array}$ & $\begin{array}{c}\text { Mean } \\
\text { Difference }\end{array}$ & $\begin{array}{c}\text { Kruskal- } \\
\text { Wallis } \\
\text { p-value }\end{array}$ \\
\hline Bust circumference & $87.7^{*}$ & $86.5 \#$ & 90.6 & $92.3^{*} \#$ & 91.7 & 90.6 & $4.6^{*}, 5.8^{\#}$ & 0.0000 \\
\hline Abdomen circumference & 84.7 & 84.1 & $80.3^{*}$ & $85.3^{*}$ & 86.6 & 88.0 & $5^{*}$ & 0.013 \\
\hline Hip circumference & $106.0^{*}$ & 102.7 & 99.1 & 99.8 * & 101.7 & 100.6 & $6.2^{*}$ & 0.0000 \\
\hline Buttocks circumference & $101.7^{*}$ & 98.7 & 95.8 & 96.9 * & 97.4 & 97.6 & $4.8^{*}$ & 0.0032 \\
\hline Thigh circumference & 61.4 *\# & $57.2^{\#}$ & 57.7 & $57.1^{*}$ & 59.4 & 56.9 & $4.2^{*}, 4.3^{\#}$ & 0.0012 \\
\hline Waist width & 25.1 & 25.6 & 24.3 & $25.5^{*}$ & 24.5 & $28.0^{*}$ & $2.5^{*}$ & 0.0000 \\
\hline Abdomen width & $29.8^{*}$ & 31.0 & $28.6^{\#}$ & $31.8^{* \#}$ & 29.9 & 32.6 & $2 *, 3.2 \#$ & 0.0000 \\
\hline Hip width & $39.7^{*}$ & $39.4^{\#}$ & 37.6 & $37.8^{*} \#$ & 38.0 & 38.2 & $1.9^{*}, 1.6^{\#}$ & 0.0004 \\
\hline Bust protrusion & $46.6^{*}$ & $45.5^{\#}$ & 48.6 & $49.3^{* \#}$ & 48.6 & 48.6 & $2.7^{*}, 3.8^{\#}$ & 0.0002 \\
\hline Abdomen protrusion & 44.8 & 45.9 & 42.8 * & $46.3^{*}$ & 44.7 & 47.0 & $3.5^{*}$ & 0.0102 \\
\hline Total body height & $161.0^{*}$ & 164.6 & $159.6 \# 1$ & 165.8 * \#1 \#2 & $157.4 \# 2 \# 3$ & $165.4 \# 3$ & $\begin{array}{l}4.8^{*}, 6.2 \# 1, \\
8.4 \# 2,8.0 \# 3\end{array}$ & 0.0000 \\
\hline Bust height & $116.0^{*}$ & 118.6 & $115.6 \# 1$ & 120.4 * \#1\#2 & 113.7 \#2 & 118.3 & $\begin{array}{c}4.4^{*}, 4^{\# 1}, \\
6.7^{\# 2},\end{array}$ & 0.0001 \\
\hline Waist height & 104.3 & 104.4 & $102.5^{*}$ & 106.0 * & 100.9 & 103.2 & $3.5^{*}$ & 0.0087 \\
\hline Bust to waist ratio & 1.25 * & $1.25 \# 1$ & 1.31 & 1.30 * \#1 \#2\#3 & $1.22 \# 2$ & $1.19 \# 3$ & $\begin{array}{c}0.05^{*} \# 1,0.08^{\# 2} \\
0.11 \# 3\end{array}$ & 0.0000 \\
\hline Hip to waist ratio & 1.51 * & $1.49 \# 1$ & 1.43 & $1.41^{*} \# 1 \# 2$ & 1.34 & $1.32 \# 2$ & $\begin{array}{c}0.1{ }^{*}, 0.08{ }^{\# 1} \\
0.09 \# 2\end{array}$ & 0.0000 \\
\hline Bust to hip & 0.82 * & $0.84 \#$ & 0.91 & $0.92^{*} \#$ & 0.91 & 0.90 & $0.1^{*}, 0.07^{\#}$ & 0.0000 \\
\hline $\begin{array}{c}\text { Total body to } \\
\text { waist height ratio }\end{array}$ & $1.55 \# 1$ & $1.58 \# 1$ & 1.55 & $1.57^{*}$ & $1.56 \# 2$ & 1.61 * \#2 & $\begin{array}{c}0.04^{*}, 0.03^{\# 1} \\
0.05 \# 2\end{array}$ & 0.0000 \\
\hline $\begin{array}{l}\text { Total body to } \\
\text { hip height }\end{array}$ & 2.07 * \# & $2.13^{\#}$ & 2.08 & $2.11^{*}$ & 2.07 & 2.12 & $0.04^{*}, 0.06 \#$ & 0.0001 \\
\hline
\end{tabular}

Bold p-values indicate significant differences at 5\%. Asterisk *,\#, \#1,\#2,\#3 denote body shape pairs significantly different at $5 \%$. Measurements are in $\mathrm{cm}$. 
Table 4 Comparison of frequency and percentage distribution of fit problems by body shape

\begin{tabular}{|c|c|c|c|c|c|c|c|c|}
\hline Body part & Fit problems & $\begin{array}{c}\text { African } \\
\text { triangle } \\
\mathrm{n}(\%)\end{array}$ & $\begin{array}{c}\text { Caucasian } \\
\text { triangle } \\
\mathrm{n}(\%)\end{array}$ & $\begin{array}{c}\text { African } \\
\text { hourglass } \\
\mathrm{n}(\%)\end{array}$ & $\begin{array}{c}\text { Caucasian } \\
\text { hourglass } \\
\mathrm{n}(\%)\end{array}$ & $\begin{array}{c}\text { African } \\
\text { rectangle } \\
\text { n (\%) }\end{array}$ & $\begin{array}{c}\text { Caucasian } \\
\text { rectangle } \\
\mathrm{n}(\%)\end{array}$ & $\begin{array}{l}\text { Total } \\
\mathrm{n}(\%)\end{array}$ \\
\hline \multirow{3}{*}{ Bust } & Tight & $14(21.9)$ & $13(31.0)$ & $10(33.3)$ & $19(37.3)$ & $2(14.3)$ & $15(46.9)^{*}$ & $13(31.0)$ \\
\hline & Loose & $19(29.7)$ & $24(57.1)^{*}$ & $10(33.3)$ & $15(29.4)$ & $5(35.7)$ & $10(31.3)$ & $83(36)$ \\
\hline & Fits & $31(48.4)^{*}$ & $5(11.9)$ & $10(33.3$ & $17(33.3)$ & $7(50)^{*}$ & $7(21.9)$ & $77(33)$ \\
\hline \multirow{3}{*}{ Stomach } & Tight & $19(29.7)$ & $13(31.0)$ & $8(26.7)$ & $26(51.0)^{*}$ & $7(50)^{*}$ & $15(46.9)^{*}$ & $88(38)$ \\
\hline & Loose & $19(29.7)$ & $6(14.3)$ & $8(26.7)$ & $3(5.9)$ & $3(21.4)$ & $6(18.8)$ & $45(19)$ \\
\hline & Fits & $26(40.6)^{*}$ & $23(54.8)^{*}$ & $14(46.7)^{*}$ & $22(43.1)$ & $4(28.6)$ & $11(34.4)$ & $100(43)$ \\
\hline \multirow{3}{*}{ Waist } & Tight & $14(21.9)$ & $12(28.6)$ & $7(23.3)$ & $21(41.2)^{*}$ & $4(28.6)$ & $8(25)$ & $66(28.3)$ \\
\hline & Loose & $35(54.7)^{*}$ & $10(23.8)$ & $12(40)^{*}$ & $10(19.6)$ & $3(21.4)$ & $13(40.6)^{*}$ & $83(35.6)$ \\
\hline & Fits & $15(23.4)$ & $20(47.6)^{*}$ & $11(36.7)$ & $20(39.2)$ & $7(50)^{*}$ & $11(34.4)$ & $84(36.1)$ \\
\hline \multirow{3}{*}{ Abdomen } & Tight & $20(31.5)$ & $13(31.0)$ & $7(23.3)$ & $28(54.9)^{*}$ & $6(42.9)^{*}$ & $16(50)^{*}$ & $90(39)$ \\
\hline & Loose & $18(28.1)$ & $5(11.9)$ & $6(20)$ & $4(7.8)$ & $3(21.4)$ & $3(9.4)$ & $39(17)$ \\
\hline & Fits & $26(40.6)^{*}$ & $24(57.1)^{*}$ & $17(56.7)^{*}$ & $19(37.3)$ & $5(35.7)$ & $13(40.6)$ & $104(44)$ \\
\hline \multirow{3}{*}{ Hips } & Tight & $43(67.2)^{*}$ & $33(78.6)^{*}$ & $12(40)^{*}$ & $33(64.7)^{*}$ & $3(21.4)$ & $15(46.9)^{*}$ & $139(60)$ \\
\hline & Loose & $9(14.1)$ & $4(9.5)$ & $12(40)^{*}$ & $5(9.8)$ & $3(21.4)$ & $4(12.5)$ & $37(16)$ \\
\hline & Fits & $12(18.8)$ & $5(11.9)$ & $6(20)$ & $13(25.6)$ & $8(57.1)^{*}$ & $13(40.6)^{*}$ & $57(24)$ \\
\hline \multirow{3}{*}{$\begin{array}{c}\text { Seat/ } \\
\text { Buttocks }\end{array}$} & Tight & $37(57.8)^{*}$ & $27(64.3)^{*}$ & $5(16.7)$ & $18(35.3)$ & $5(35.7)$ & $13(40.6)$ & $105(45)$ \\
\hline & Loose & $8(12.5)$ & $6(14.3)$ & $12(40)^{*}$ & $14(27.5)$ & $5(35.7)$ & $5(15.6)$ & $50(21)$ \\
\hline & Fits & $19(29.7)$ & $9(21.4)$ & $13(43.3)^{*}$ & $19(37.3)$ & $4(28.6)$ & $14(43.7)^{*}$ & $78(34)$ \\
\hline \multirow{3}{*}{ Thighs } & Tight & $41(64.1)^{*}$ & $34(81.0)^{*}$ & $12(40)^{*}$ & $34(66.7)^{*}$ & $2(14.3)$ & $19(59.4)^{*}$ & $142(61)$ \\
\hline & Loose & $5(7.8)$ & $0(0)$ & $9(30)$ & $9(17.7)$ & $4(28.6)$ & $3(9.4)$ & 30 (13) \\
\hline & Fits & $18(28.1)$ & $8(19.1)$ & $9(30)$ & $8(15.7)$ & $8(57.1)^{*}$ & $10(31.3)$ & $61(26)$ \\
\hline \multicolumn{2}{|c|}{ Total } & 64 & 42 & 30 & 51 & 14 & 32 & $233(100)$ \\
\hline
\end{tabular}

* Bold figures with asterisks indicate a majority of participants at each body part and fit category per body shape. 
shapes had significantly smaller busts than the Caucasian hourglass and were therefore expected to experience a loose fit. The literature (Rasband \& Liechty, 2006:202) confirms that triangular shapes have smaller upper bodies (i.e. bust, stomach and waist) than average and are expected to experience a loose fit at these body parts. However, the findings of this study indicate that the two triangular shapes reported different fit problems at the bust, as $48.4 \%$ of the African triangle reported a good fit, whereas $57.1 \%$ of the Caucasian triangle reported a loose fit - as was predicted in the literature. Waist measurements of both African and Caucasian triangles showed no significant difference from those of the Caucasian hourglass, as expected; moreover, $47.6 \%$ of the Caucasian triangle reported no fit problems. However, it was inconsistent with the literature that $54.7 \%$ of the African triangle reported a loose fit at the waist, and a majority reported good fit at the bust and the waist. This might be because of the wide thighs of the African triangle. Participants might have bought the garment to fit the widest part of the body, namely the thighs, resulting in a too loose fit at the waist. Muthambi (2012), who also used this research project's data to develop sizing for young African women with triangular shaped bodies, found that participants required a basic sheath dress (as is commonly used in the industry) that was two sizes larger to accommodate the large thighs, resulting in a loose fit around the waist, midriff and bust. Stomach and abdomen measurements of both triangles recorded no significant differences from those of the Caucasian hourglass; hence a good fit was to be expected, as it was reported. However, this was inconsistent with the literature, as garments meant to fit wider hips, fit loosely at the smaller and tapering stomach, waist and abdomen (Rasband \& Liechty, 2006:210).

The literature records that triangular shapes also have larger lower bodies, i.e. hips, seat and thighs, and are expected to experience apparel tightness at these body parts (Rasband \& Liechty, 2006:24). This was confirmed by the measurements, as African triangular shapes recorded significantly larger hips and seat than the Caucasian hourglass shapes. On the other hand, the Caucasian triangle had significantly larger thighs than the Caucasian hourglass. The findings on fit problems indicated that more than $50 \%$ of the African and Caucasian triangles reported apparel tightness at their lower bodies, which was in accordance with the literature records. 


\section{Comparison of fit problems of the Caucasian hourglass and the African}

hourglass: The abdomen circumference, abdomen width and abdomen protrusion of the African hourglass were significantly less than those of the Caucasian hourglass. As the South African apparel industry still mainly bases their sizing on the measurements of the Western hourglass, one would have expected that the Caucasian hourglass would report no fit problems, while the African hourglass might report loose fitting around the abdomen. Table 4, however, shows that most of the African hourglass shapes reported no fit problems at the stomach (46.7\%), abdomen (56.7\%), seat (43.3\%) or thighs (40\%), and $40 \%$ reported a loose fit around the waist, seat and hips, whereas a majority of the Caucasian hourglass reported a too tight fit around the stomach (51\%), waist (41.2\%), abdomen (54.9\%) and thighs (66.7\%). It is worth noting that the tight fit problems reported by a majority of the Caucasian (Western) hourglass at all the other body parts were also unexpected, as the industry is believed to be basing ready-to-wear apparel manufacturing on the standard or Western hourglass figure. Yet, the problems experienced by the Caucasian hourglass suggest that the standard figure or Western hourglass used by the apparel industry might also be different from the Caucasian hourglass identified in this study.

\section{Comparison of fit problems of the Caucasian hourglass and the African and} Caucasian rectangle: The literature (Rasband \& Liechty, 2006:25) states that a rectangular shape has an average to large bust, mid-section (namely stomach, waist and abdomen) and hips, seat and thighs which are almost equal - thus resembling a rectangle. This body shape is therefore expected to experience apparel tightness at all these body parts. The findings of this study reveal no significant differences in all the measurements of both the African and the Caucasian rectangular shapes on the one hand, and those of the Caucasian hourglass on the other, except at the waist, where the Caucasian rectangular shape had a significantly wider waist than the Caucasian hourglass (Table 4). This is the main difference between the hourglass and rectangular shapes recorded in the literature. As a result, the latter is expected to have fit tightness at the waist. On the contrary, Table 4 shows that $46.9 \%$ of the Caucasian rectangle reported loose fit, and $50 \%$ of the African rectangle reported good fit at the waist, which was inconsistent with the literature (Rasband \& Liechty, 2006:206). However, as can be expected, both the African and the Caucasian rectangles reported tight fit 
around the stomach (50\% and 51\% respectively) and abdomen (42.9\% and 54.9\% respectively).

\section{Conclusions and implications}

In this study, the bust, waist and hip drop values and visual verification were successfully used to classify the body shapes of the young African and Caucasian women between the ages of 18 and 25 years. As the literature suggests, this study confirmed that body shape prevalence, body measurements and body shape characteristics differ between ethnic groups. Differences in body dimensions as well as body shape characteristics were also observed between similar African and Caucasian body shapes.

It can be concluded that by far the most prevalent body shape amongst the African group was the triangular shape (58.7\%), followed by the hourglass shape $(27.5 \%)$ and the rectangular shape (12.8\%). Amongst the Caucasian group the most prevalent body shape was the hourglass shape (40.8\%), followed by the triangular shape (33.6\%) and the rectangular shape $(25.6 \%)$. This is contrary to what was found in other Western and non-Western studies. Lee et al. (2004) discovered that the most prevalent shape amongst USA and Korean women was the rectangle; Mastamet-Mason et al. (2012) also found that the distinctive body shape in Kenya was the rectangle, although with distinct differences between the Kenyan and Western rectangular shapes. Considering that ready-made apparel items in South Africa are still mainly designed and sized according to the ideal (hourglass) Western body shape, this means that by far the most African and Caucasian young female consumers' bodies differ from what is still seen by the industry as the ideal and most common body shape. They are therefore likely to have difficulties in finding apparel items that fit well.

It may further be concluded that body shape characteristics differ between African and Caucasian women with the same body shapes - probably due to ethnic differences. The abdomen circumference, abdomen width and abdomen protrusion of the so-called ideal Caucasian hourglass were, for example, significantly wider than those of the African hourglass, while the thigh circumference of the most prevalent 
African triangle was significantly more than that of the Caucasian triangle. This confirms the studies of Lee et al. (2007) and Mastamet-Mason et al. (2012), who concluded that body shape characteristics of the same shape differ between ethnic groups. In constructing apparel for a diverse target market, it is therefore crucial that the apparel industry pays attention to these existing differences in body shape characteristics.

In order to predict any fit problems, selected body measurements and the ratios of all the other African and Caucasian shapes were further compared to those of the Caucasian hourglass (mostly used by industry for sizing and fit evaluation). This study confirms the results from previous studies (Simmons et al., 2004; Connell et al., 2006; Lee et al., 2007), as significant differences were found between both the African and the Caucasian triangular and rectangular shapes on the one hand, and the Western hourglass shape on the other. In most cases, predicted fit problems were confirmed by the African and the Caucasian respondents' perceived fit problems. Specifically the Caucasian rectangle reported fit problems at all body parts, while both the Caucasian and African triangle reported a tight fit around the hips, buttocks and thighs. There were, however, in some cases discrepancies between the expected fit problems and the perceived fit problems as reported by the respondents. It should, however, be noted that the perceived fit problems are subjective and may also be influenced by other factors, such as fit preferences and body cathexis.

Apparel manufacturers and retailers who wish to target diverse multi-cultural markets need to be cognizant of the differences between the body shapes and body shape characteristics of different ethnic groups. Furthermore, it would be unrealistic for apparel industries to persist in manufacturing styles that are suitable for the hourglass body shape, and expect them to fit all the other body shapes. The quality of apparel in respect of its fit can only be determined collectively, through dress forms, fit models and sizing systems, which all have to represent the target population's sizes and body shapes. Understanding the underlying differences in body shape could help designers to translate the distinct body characteristics into better-fitting apparel items. Fit models as well as dress forms chosen for fit testing and modelling in the apparel industry, should reflect the characteristics of all the most prevalent shapes. 


\section{References}

Alexander, M., Connell, L.J. \& Presley, A.B. (2005) Clothing fit preferences of young female consumers. International Journal of Clothing Science and Technology, 17, $52-$ 64.

Anderson, L.J., Brannon, L.E., Ulrich, P.V. Presley, A.B., Waronka, D., Grasso, M. \& Stevenson. D. (2001) Understanding fitting preferences of female consumers: development of an expert system to enhance accurate sizing selection. National Textile Centre Annual Report, 198-A08.

Ashdown, S.P. (1998) An investigation of the structure of sizing systems: a comparison of three multidimensional optimized sizing systems generated from anthropometric data with the ASMT standard D5585-9. International Journal of Clothing Science and Technology, 10, 324-341.

Ashdown, S.P. (2000) Introduction to sizing and fit research. RESEARCH FIT. 2000.

The Fit symposium: Clemson Apparel Research Centre. Clemson. SC. [Online] Available: http://car.clemson.edu/fit2000/ (Accessed on 6 March 2009).

Ashdown, S.P. 2003. The three-dimensional scanner: ready-to-wear. [Online] Available: $\quad$ http://www.explore.cornell.edu/scene=the\%203d\%20body\%scanner (accessed on 28 August 2009).

Ashdown, S.P. (2007) (Ed.) Sizing in clothing: developing effective sizing systems for ready to wear clothing. Wood Head Publishing Ltd., New York.

Beazley, A. (1998) Size and fit: the development of size charts for clothing. Part 3. Journal of Fashion Marketing and Management, 3, 66-84.

Bye, E.K., LaBat, K.L. \& DeLong, M.R. (2006) Analysis of body measurement systems for apparel. Clothing and Textiles Research Journal in International Textile and Apparel Association, 24, 66-79.

Chun-Yoon, J. \& Jasper, C.R. (1996) Key dimensions of women's ready-to-wear apparel: developing consumer size-labelling system. Clothing and Textile Research Journal, 14, 89-95.

Connell, L.J., Ulrich, P.V., Brannon, E.L., Alexander, M. \& Presley, A.B. (2006) Body shape assessment scale: instrument development for analysing female figures. Clothing and Textiles Research Journal, 24, 80-95. 
DeLong, M., Ashdown. S., Butterfield, L. \& Turnbladh, K.F. (1993) Data specifications needed for apparel production using computers. Clothing Textiles Research Journal, 11, 1-7.

Devarajan, P. \& Istook, K. (2004) Validation of female figure identification technique (FFIT) for apparel software. Journal of Textile and Apparel Technology and Management, 4, 1-23.

Fan, J. (2004) Perception of body appearance and its relation to clothing. In Fan, J., Yu, W. \& Hunter, L. (2004) (Eds.), Clothing Appearance and Fit: Science and Technology. Wood Head Publishing Ltd, New York.

Goldsberry, E., Shim, M. \& Reich, N. (1996) Women 55 and older: Part II. Overall satisfaction and dissatisfaction with fit of ready-to-wear. Clothing and Textiles Research Journal, 10, 37-45.

Gupta, D. \& Gangadhar, B.R. (2004) A statistical model for developing body size charts for garments. International Journal of Clothing Science and Technology, 16(5), 485-469.

Hillestad, R. (1980) Underlying structure of appearance. Dress, 6, 117-125.

ISO/DIS 20685. (2010) 3D scanning methodologies for internationally compatible anthropometric databases. European Committee for Standardization. Brussels.

Istook, C.L. \& Hwang, S.J. (2001) Body scanning systems with application to the apparel industry. Journal of Fashion Marketing and Management, 5, 120-132.

Lee, Y.M., Istook, C.L., Nam, Y.J. \& Park, S.M. (2007) Comparison of body shape between USA and Korean women, International Journal of Clothing Service and Technology, 19(5), 374-391.

Mastamet-Mason, A. (2008) An explication of the problems with apparel fit experienced by female Kenyan consumers in terms of their unique body shape characteristics. PhD Consumer Science, Thesis, University of Pretoria.

Mastamet-Mason, A, De Klerk, H.M. \& Ashdown, S.P. (2012) Identification of a unique African female body shape. International Journal of Fashion Design, Technology and Education. 5(2), 105-116.

Muthambi, A. (2012) Proposed sizing for young South African women of African descent with triangular shaped bodies. Masters Consumer Science, Dissertation, University of Pretoria. 
Otieno, R., Harrow, C. \& Lea-Greenwood, G. (2005) The unhappy shopper, a retail experience: exploring fashion, fit and affordability. International Journal of Retail and Distribution management, 33(4), 289-309.

Petrova, A. (2007) Creating sizing systems. In Ashdown, S.P. (Ed.), Sizing in clothing: developing effective sizing systems for ready-to-wear clothing. Wood Head Publishing Ltd., New York.

Pisut, G. \& Connell, L.J. (2007) Fit preferences of female consumers in USA. Journal of Fashion Marketing, 11, 366-379.

Rasband, J. (1994) Fabulous fit. Fairchild Publications, New York.

Rasband, J. \& Liechty, E. (2006) Fabulous fit, 2nd edn. Fairchild Publications, New York.

Simmons, K. \& Istook, C.L. (2003) Body measurement techniques, comparing 3-D body-scanning and anthropometric methods of apparel applications. Journal of Fashion Marketing and Management, 7, 306-332.

Simmons, K., Istook, C.L. \& Devarajan, P. (2004) Female figure identification technique (FFIT) for apparel. Part 1: describing female shapes. Journal of Textile and Apparel Technology and Management, 4, 1-5.

Strydom, M. \& De Klerk, H.M. (2006) The South African clothing industry: problems experienced with body measurements. Journal of Family Ecology and Consumer Sciences, 34, 80-89.

Wang, M.J., Wu, W.Y., Lin, K.C., Yang, S.H. \& Lu, J.M. (2007) Automated anthropometric data collection from three-dimensional digital human models. International Journal of Advanced Manufacturing Technology, 32, 109-115.

Winks, J.M. (1997) Clothing sizing, international standardization, The textile Institute, Redwood Books, London.

Xu, B., Huang, Y., Yu, W. \& Chen, T. (2002) Three-dimensional body scanning system for apparel mass customization. Society of Photo-Optical Instrumentation Engineers, 41, 1475-1479.

Yu, (2004) Subjective assessment of clothing. In Fan, J., Yu, W. \& Hunter, L. (2004) (Eds.), Clothing appearance and fit: science and technology, Wood Head Publishing Ltd, New York.

Zwane, P.E. \& Magagula, N. (2006) Pattern design for women with proportionate figures: a case study for Swaziland. International Journal of Consumer Studies, 31, 283-287. 